J. Amer. Soc. Hort. ScI. 127(6):938-943. 2002.

\title{
A Single Recessive Gene for Sucrose Accumulation in Cucumis melo Fruit
}

\author{
Yosef Burger, Uzi Saar, Nurit Katzir, and Harry S. Paris \\ Department of Vegetable Crops, Newe Ya' ar Research Center, POB 1021, Ramat Yishay, 30095, Israel \\ Yelena Yeselson, Ilan Levin, and Arthur A. Schaffer ${ }^{1}$ \\ Department of Vegetable Crops and Plant Genetics, Volcani Center, AgriculturalResearch Organization, \\ P.O. Box 6, Bet Dagan, 50250, Israel
}

\begin{abstract}
AdDitional INDEX WORDs. soluble sugars, hexose, glucose, fructose, fruit quality, QTL
Abstract. Fruit sweetness is the major determinant of fruit quality in melons (Cucumis melo L.) and reflects the concentration of the three major soluble sugars, sucrose, glucose, and fructose, present in the fruit flesh. Of these three sugars, sucrose is the prime factor accounting for both the genetic and the environmental variability observed in sugar content of $\boldsymbol{C}$. melo fruit. Faqqous (subsp. melo var. flexuosus), a cultivar having a low sucrose and total sugar content, was crossed with Noy Yizre'el (subsp. melo var. reticulatus), a cultivar having a high sucrose and total sugar content. $\mathrm{F}_{1}$ plants had a sucrose content averaging slightly higher than that of the low-sucrose parent, indicating that low sucrose content is nearly completely dominant. Segregation in the $F_{2}$ and backcross progenies indicated that high sucrose accumulation in melon fruit flesh is conferred by a single recessive gene herein designated suc. When the high-sucrose parent was crossed with the moderate-sucrose landrace known as Persia 202 (subsp. melo var. reticulatus), the segregation in the filial and backcross progenies suggested that additional genetic factors affect the amount of sucrose accumulation.
\end{abstract}

Sugar concentration in the fruit flesh is the most important factor determining fruit quality in sweet melons (Cucumis melo L.) (Yamaguchi et al., 1977). The sugar content in the mature fruit is the product of complex developmental source-sink relationships in the melon plant. It includes the metabolism of assimilates and their partitioning among the various sinks, especially the metabolism of photoassimilates in the developing fruit sink, which determines the fate of the imported assimilates (Schaffer et al., 1996).

The major components of the soluble sugar fraction of the ripe melon fruit are sucrose, glucose and fructose. Developmentally, the increase in sugar content during ripening is primarily a function of the accumulated sucrose, while glucose and fructose levels fluctuate much less, if at all (Hubbard et al., 1989; Hughes and Yamaguchi, 1983; Lester and Dunlap, 1985; McCollum et al., 1988; Pratt, 1971; Rosa, 1928; Schaffer et al., 1987, 1996). The melon fruit undergoes a phase of developmental transition in sugar metabolism in which the early period of fruit growth is characterized by the absence of sucrose and is followed by a later period of sucrose accumulation, which continues until abscission or harvest. Because the melon fruit contains no starch reserves (Rosa, 1928) there is no net increase in sugar content after harvest. Therefore, the accumulation of sucrose during fruit development and maturity is the most important variable in determining fruit quality.

Both environmental and genetic factors influence the sucrose content of $C$. melo fruit. The large environmental variability in total sugar content of commercial hybrid varieties is due primarily to differences in sucrose levels and not hexose levels (Burger

Received for publication: 26 Feb. 2002. Accepted for publication 23 July 2002. This research project was funded in part by U.S.-Israel Binational Agricultural Research and Development (BARD) grants 1063-86 and 2270-93. The authors thank Shmuel Shen and Miriam Fogelman for expert technical assistance and Rivka Barg, Ilan Paran, and Nissim Yonash for reading the manuscript and for their helpful suggestions. This paper is contribution 106/2002 from the Institute of Field and Garden Crops, Agricultural Research Organization, Bet Dagan, Israel.

'Corresponding author: e-mail vcaris@volcani.agri.gov.il. et al., 2000). Similarly, the large genetic variability observed within the C. melo species for total sugar concentration is also accounted for by differences particularly in the levels of sucrose (Burger et al., 2000, Hubbard et al., 1989; Stepansky et al., 1999). Within the C. melo species there exists a continuum of genotypes ranging from low sugar types with no sucrose accumulation to those with high sucrose levels characteristic of the high-sugar, sweet-melon cultivars (Stepansky et al., 1999).

The goal of this study was to conduct a genetic analysis of sugar levels in segregating populations. These populations were derived from crosses between genotypes of $C$. melo with low and high, as well as medium and high, sucrose levels in the mature fruit. Our results indicate that the trait of sucrose accumulation is highly heritable and that a major gene determines the difference between the low and high sucrose genotypes.

\section{Materials and Methods}

Plant material. Three accessions of $C$. melo, the high-sugar cultivar from Israel Noy Yizre'el (NY, subsp. melo var. reticulatus), a birdsnest medium-sugar landrace from Iran designated Persia 202 (P202, subsp. melo var. reticulatus) (Paris et al., 1985), and a low-sugar cultivar Faqqous (FAQ, subsp. melo var. flexuosus), were grown in the field in the spring. FAQ is consumed as a young fruit, similar to cucumber (Cucumis sativus $\mathrm{L}$.). Inbred lines after at least six generations of self-pollination were used in this study. Controlled crosses were made between the high-sugar (NY) and the low-sugar (FAQ) and medium-sugar (P202) genotypes. $\mathrm{F}_{1}, \mathrm{~F}_{2}$, and backcross populations were generated and all were grown as a spring crop in the field. Flowers were tagged at anthesis and allowed to open pollinate. One mature fruit from each individual plant (as delineated in Table 4) was harvested and sampled as above. Maturity was determined as the onset of pedicel abscission. The NY x FAQ populations were grown in two seasons, spring, 1993 (population I) and again in the spring, 2000 (population II). The NY x P202 populations were grown in the spring of 1992.

Sugar Measurements. About $1 \mathrm{~g}$ fresh weight of middle 
mesocarp tissue from the central cross section of the ripe harvested fruit was weighed and placed in $80 \%$ ethanol. Soluble sugars were removed by three successive extractions at $70^{\circ} \mathrm{C}$ and, following evaporation, the sugars were resuspended in doubledistilled water. Samples were passed through a $0.45-\mathrm{mm}$ filter and sugars were separated and identified by HPLC equipped with a refractive index detector (Shimadzu) using a Bio-Rad Fast Carbohydrate column, according to the manufacturer's instructions, as in Miron and Schaffer (1991).

STATISTICAL ANALYSES. Statistical analyses of heritabilities were carried out using the JMP Statistical Discovery software version 3.1 (SAS Institute Inc., Cary, N.C.). Broad and narrow sense heritability estimates of individual fruit sugar levels and total soluble sugars were calculated based on a combination of variation components and genetic effects, both additive and dominant (Falconer, 1995). These genetic components were calculated on the basis of sugar accumulation performances by the parental, filial, and backcross populations. The analysis of effects allowed for the large nongenetic variability in sugar content of the high-sucrose genotypes which we previously described (Burger et al., 2000).

\section{Results}

The sugar levels of the three parental genotypes, representing low (FAQ), medium (P202) and high (NY) sucrose accumulation, are shown in Table 1. The differences in total sugar levels between the low and high sucrose parents are accounted for by the differences in sucrose content while the hexose (glucose and fructose) levels do not contribute to the differences in sugar levels. The medium- sucrose genotype (P202) had about half the sucrose concentration as the NY parent as well as slightly lower glucose and fructose levels.

In order to study the heritability and inheritance of the trait of sucrose accumulation, segregating populations derived from the cross between the high (NY) and low (FAQ) as well as between the high (NY) and medium (P202) sugar lines were analyzed. Table 2 shows the heritability estimates for Brix (TSS), total sugars, and each of the individual sugars based on the results of the segregating populations. High heritability estimates were obtained for sucrose levels in the NY x FAQ crosses but low estimates were obtained for the hexose sugars. Accordingly, the high heritability estimates for Brix values and total sugar content can be accounted for primarily by the sucrose component. In contrast, in the NY x P202 population the heritability estimates for Brix, total sugars and individual sugars, including the sucrose component, were all low (Table 2).

INHERITANCE OF HIGH X LOW SUGAR CONTENT. The segregation study for sugar concentration in the NY $x$ FAQ populations was repeated in two different seasons and the general pattern of results was similar. Figs. 1 and 2 show the distribution of the various sugar components in the parental, filial, and backcross populations. The hexose levels were not significantly different between the two parents in either season (Table 1).

The wide range of sucrose values in the inbred homogenetic high-sucrose parent (Figs. 1 and 2, NY) is characteristic of this trait and is nongenetic variability. Nevertheless, characteristic ranges of sucrose levels could be discerned in the different segregating populations (Table 3 ). The high sucrose NY parent exhibited a broad range of sucrose levels, from individuals with low values of 14 and $27 \mathrm{mg} \cdot \mathrm{g}^{-1}$ fresh weight in the two experiments (years) to high values of $\approx 50 \mathrm{mg} \cdot \mathrm{g}^{-1}$ fresh weight. The low sucrose parent showed a narrow range of sucrose, with maximum levels of 4 and $6 \mathrm{mg} \cdot \mathrm{g}^{-1}$ fresh weight in the two seasons. In both seasons, the $F_{1}$ was intermediate in mean sucrose values with low range individuals overlapping the low sugar parent and high range individuals approaching the lowest individual of the high sucrose parent (Table 3). The first BC-NY population (population $\mathrm{I})$ of 20 individuals spanned the intermediate $\left(\mathrm{F}_{1}\right.$ range) to high values of sucrose with no low-sucrose individuals but the small population did not show a separation into two distinct classes of intermediate and high sucrose levels. The second BCNY population (population II) of 49 individuals also spanned the intermediate and high ranges with no low sucrose individuals but showed separation into two approximately equal classes (Fig. 2, Table 4). The BC-FAQ population in both seasons showed individuals only in the low and intermediate sucrose ranges, with no individuals in the high-sucrose range.

The segregation of sucrose values in the $\mathrm{F}_{2}$ population showed a bimodal distribution in the first season (Fig. 1) and a bimodal distribution with continuity in the second season (Fig. 2). In light of the overlap between the classes of low and intermediate sucrose levels, the goodness-of-fit analysis was performed based on separation into only two, rather than three, classes: 1) low (FAQ range) + intermediate $\left(\mathrm{F}_{1}\right.$ range $)$ sucrose levels, and 2$)$ high (NY range) sucrose values. Based on the ranges of the parental, filial and backcross populations (Table 3) and the distribution patterns of the $F_{2}$ populations (Figs. 1 and 2), cutoff values between the high and the low and medium sucrose classes were 15 and $18 \mathrm{mg}$ sucrose for the two seasons, respectively. The data were consistent with a single major gene determining sucrose levels (Table 4). In both seasons, about $1 / 4$ of the population showed the higher values characteristic of the range of sucrose in the high-sugar parent and the remaining $3 / 4$ had sucrose levels in the range of the low and intermediate sucrose values (Table 4). Because the mean comparisons (Table 3 ) point to an intermediate effect in the $F_{1}$ but are nonetheless skewed toward the lowsucrose parent, the inheritance of sucrose accumulation can be described as being controlled by a single incompletely dominant gene for low sucrose content. Because there is no clear demarcation between the low and intermediate sucrose values, we do not present the goodness-of-fit analysis for a 1:2:1 ratio. However, a cutoff value of 3 to $4 \mathrm{mg}$ sucrose, which lies at the interface between the FAQ and the $F_{1}$ populations, allows for the segregation of the $F_{2}$ populations into such a ratio (not shown).

INHERITANCE OF HIGH $X$ INTERMEDIATE SUGAR CONTENT. The intermediate-sugar line (P202) accumulates sucrose to levels of about one-half of that of the high-sugar NY. This difference in the sucrose component accounts for $\approx 70 \%$ of the difference in the total sugar content of the parents (Table 1). There are also small differences between the parents in the hexose components, which contribute the remaining differences in total sugar content. The behavior of the $F_{1}$ indicates dominant components for high sucrose content and dominant components for low hexose content. However, the distribution of sucrose and hexose contents in the segregating $\mathrm{BC}$ and $\mathrm{F}_{2}$ populations do not indicate a simple qualitative mode of inheritance (Fig. 3). Of significance is the observation that in the $\mathrm{F}_{2}$ population there are no segregates with sucrose levels in the range of the low sucrose line, FAQ.

\section{Discussion}

The results obtained from the cross between the low- and highsucrose phenotypes (FAQ $\times$ NY) support a simple mode of 
Table 1. Sugar levels $\left({\mathrm{mg} \cdot \mathrm{g}^{-1}}^{-1}\right.$ resh $\left.\mathrm{wt}+\mathrm{SE}\right)$ in the mature fruit of three parental inbreds of Cucumis melo.

\begin{tabular}{lccc}
\hline \hline & Total & & \\
Inbred & sugars & Sucrose & Glucose \\
\hline Expt.1 (1993) & $20.4 \pm 4.7$ & $1.7 \pm 0.7$ & $8.3 \pm 2.7$ \\
$\quad$ FAQ & $50.3 \pm 11.6$ & $27.7 \pm 9.9$ & $11.6 \pm 1.7$ \\
NY & & & $10.4 \pm 2.8$ \\
Expt. 2 (2000) & $30.1 \pm 9.1$ & $2.3 \pm 1.9$ & $13.0 \pm 3.3$ \\
FAQ & $64.3 \pm 7.4$ & $35.3 \pm 8.1$ & $13.3 \pm 2.0$ \\
NY & $36.0 \pm 4.3$ & $18.4 \pm 2.1$ & $14.8 \pm 4.5$ \\
Expt. 3 & $59.6 \pm 12.1$ & $35.6 \pm 10.5$ & $9.4 \pm 3.4$ \\
P202 & & $12.6 \pm 3.0$ & $8.2 \pm 2.4$ \\
NY & & $11.3 \pm 1.7$ \\
\hline
\end{tabular}

Table 2. Heritability estimates of Brix (TSS) and soluble sugar components in mature Cucumis melo fruit from populations derived from crosses of NY FAQ and NY P202

\begin{tabular}{|c|c|c|c|c|c|c|}
\hline Population & Heritability $^{\mathrm{z}}$ & TSS & $\begin{array}{c}\text { Total } \\
\text { sugars }\end{array}$ & Sucrose & Glucose & Fructose \\
\hline \multirow[t]{2}{*}{ NY FAQ \#1 } & $\mathrm{H}^{2}$ & 0.79 & 0.66 & 0.76 & 0.23 & 0.31 \\
\hline & $h^{2}$ & 0.75 & 0.64 & 0.62 & 0.18 & 0.0 \\
\hline NY FAQ \#2 & $h^{2}$ & 0.63 & 0.65 & 0.72 & 0.27 & 0.02 \\
\hline \multirow[t]{2}{*}{ NY P202 } & $\mathrm{H}^{2}$ & 0.43 & 0.42 & 0.39 & 0.25 & 0.38 \\
\hline & $h^{2}$ & 0.23 & 0.37 & 0.27 & 0.18 & 0.35 \\
\hline
\end{tabular}

${ }^{\mathrm{z}} \mathrm{H}^{2}$, broad sense heritability; $\mathrm{h}^{2}$, narrow sense heritability, calculated according to Falconer (1995).

inheritance of sucrose levels that can largely be accounted for by a single recessive gene for high sucrose accumulation, hereby designated suc. Dominance for low accumulation of sucrose is not complete, however, as is evident by the low-to-intermediate sucrose accumulation of the $F_{1}$ and the segregation pattern of the backcross and $F_{2}$ populations. The wide range of sucrose values in the homogenetic populations $\left(\mathrm{P}_{1}\right.$ and $\left.\mathrm{F}_{1}\right)$ partially confounds the classification of phenotypes in the segregating populations but the inheritance pattern of a major gene is nevertheless consistent with the data. Furthermore, our data show that of the major individual sugars contributing to the soluble sugar content of melon fruit only sucrose levels are highly heritable.

Although sugar and sucrose accumulation are quantitative traits, it is not surprising that a major gene is involved in conditioning sugar levels. Other quantitative traits for fruit quality components that are conditioned by major genes are, for

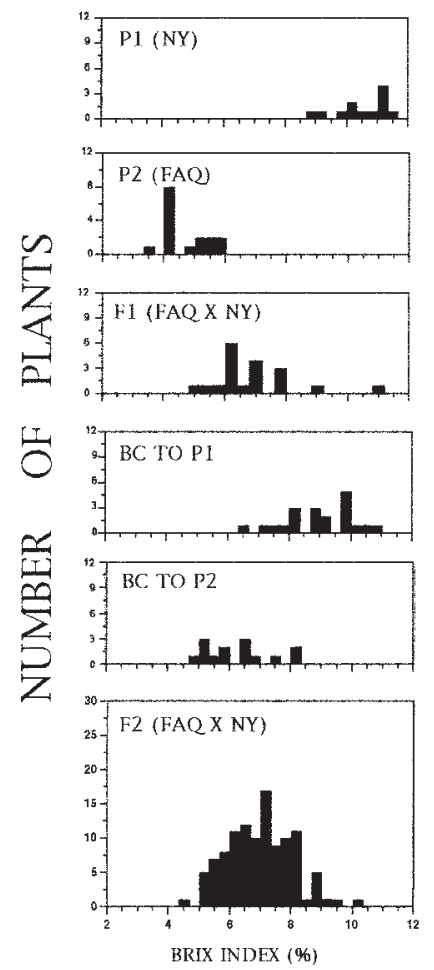

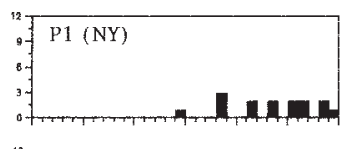
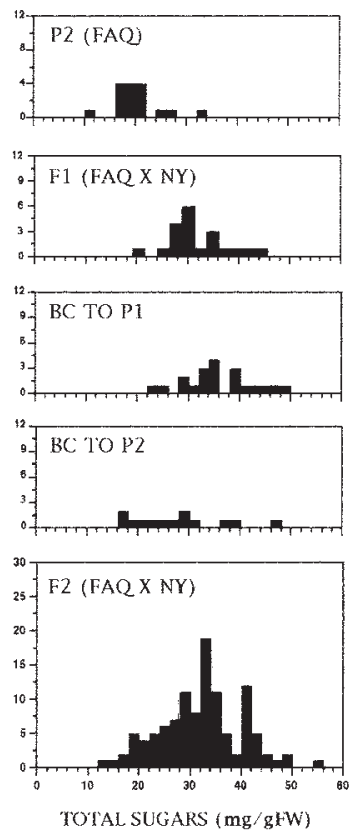
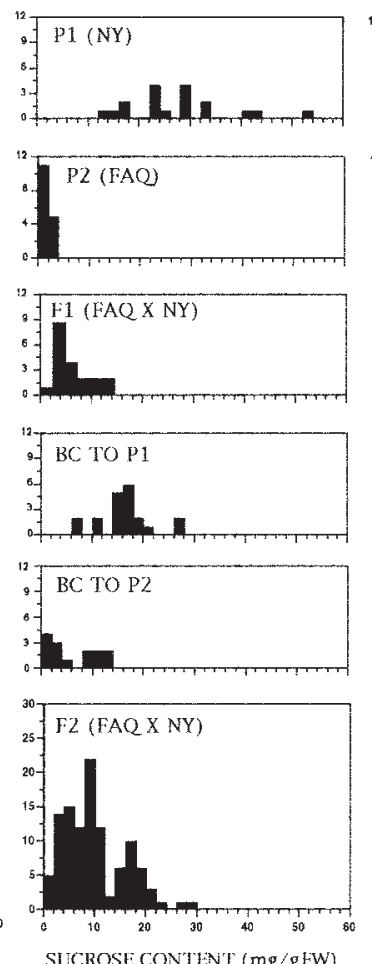
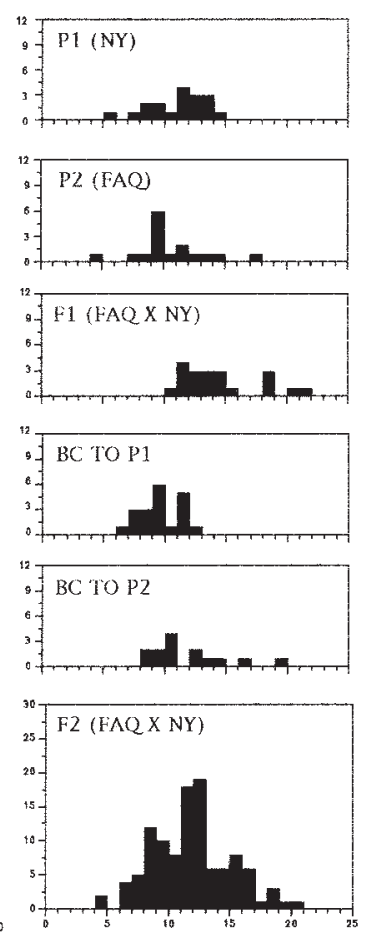

HRUCTOSE CONTENT (mg/gFW)
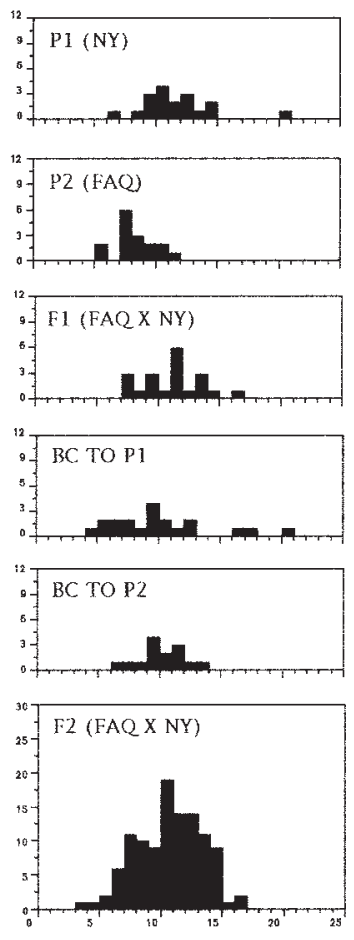

GIUCOSE CONTENT (mg/gFW)

Fig. 1. Frequency distribution of Brix, total soluble sugars, and individual sugars in progeny of populations based on NY and FAQ, first season. 


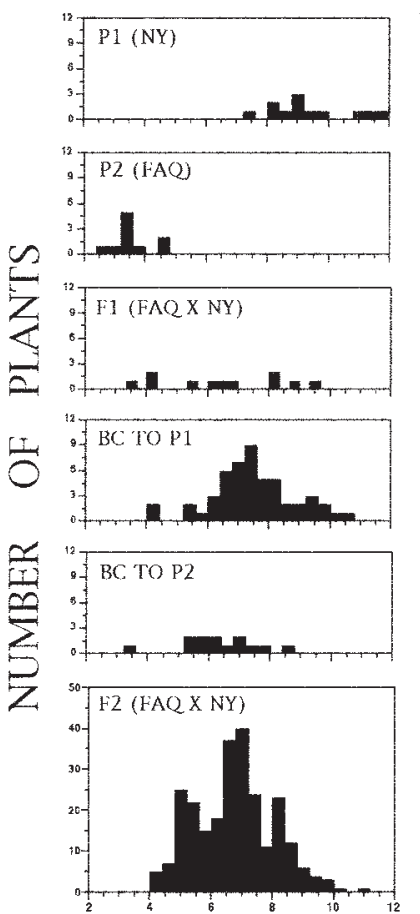

BRIX INDEX (\%)
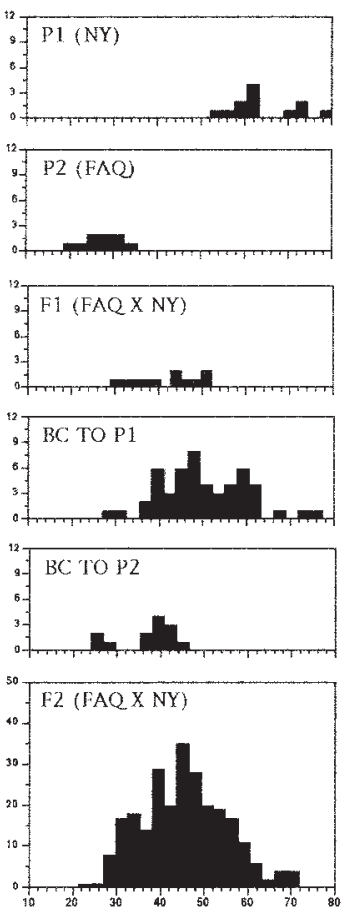

TOTAL SUGARS $(\mathrm{mg} / \mathrm{gFW})$
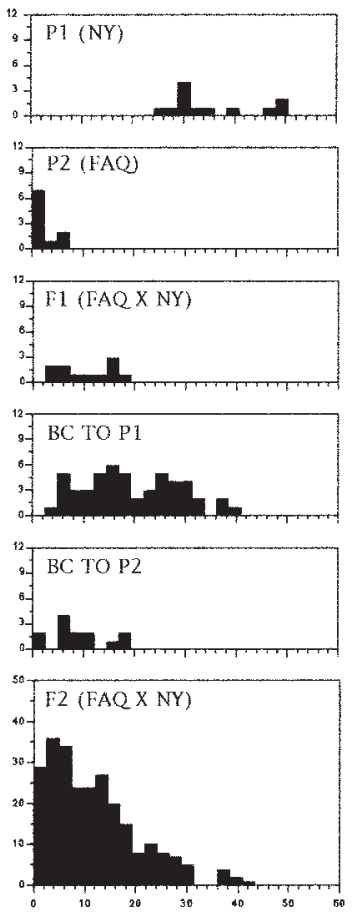

SUCROSE CONTENT ( $\mathrm{mg} / \mathrm{gFW}$ )
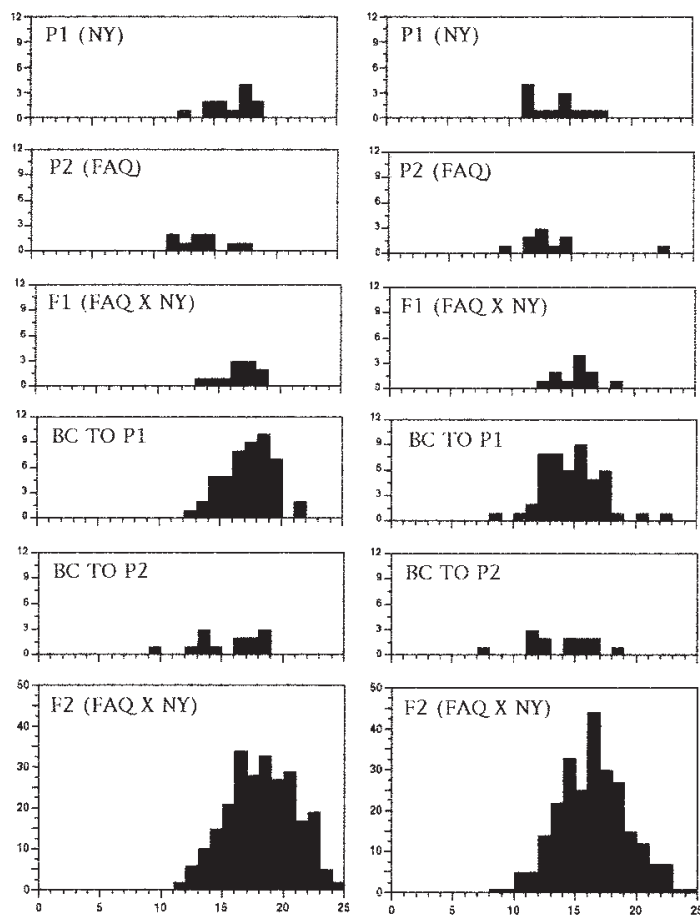

FRUCTOSE CONTENT (mg/gFW)
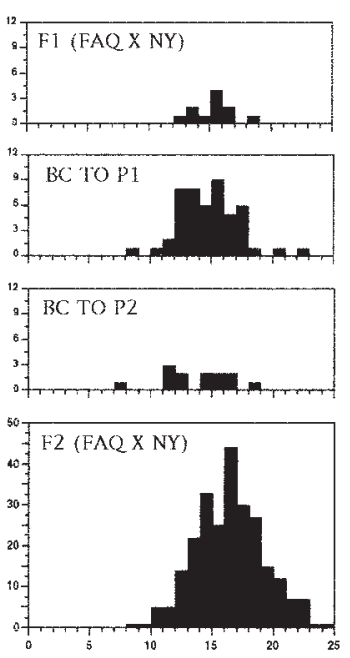

GIUCOSE CONTENT (mg/gFW)

Fig. 2. Frequency distribution of Brix, total soluble sugars, and individual sugars in progeny of populations based on NY and FAQ, second season.

Table 3. Means and ranges of sucrose concentrations in fruit of NY, FAQ, and the genetic populations derived from the cross between them.

\begin{tabular}{|c|c|c|c|c|c|c|}
\hline \multirow[b]{2}{*}{ Population } & \multicolumn{6}{|c|}{ Sucrose $\left(\mathrm{mg} \cdot \mathrm{g}^{-1}\right.$ fresh wt) } \\
\hline & Mean & Range & $\mathrm{N}^{\mathrm{y}}$ & Mean & Range & $\mathrm{N}$ \\
\hline P2 (FAQ) & $2 \mathrm{~d}$ & $0-4$ & 16 & $3 d$ & $0-6$ & 10 \\
\hline $\mathrm{F}_{1}$ & $6 \mathrm{c}$ & $1-13$ & 20 & $10 \mathrm{c}$ & $3-18$ & 11 \\
\hline BC-P1 & $16 \mathrm{~b}$ & $7-28$ & 20 & $21 \mathrm{~b}$ & $5-40$ & 49 \\
\hline
\end{tabular}

${ }^{\mathrm{z}}$ Letters in the mean column indicate significant differences at $P=0.05$ (Student-Neuman-Keuls).

y Number of individuals.

Table 4. Segregation for sucrose content of the mature fruit flesh in crosses of NYwith FAQ.

\begin{tabular}{|c|c|c|c|c|c|c|}
\hline \multirow[b]{2}{*}{ Generation } & \multicolumn{3}{|c|}{ No. of plants } & \multirow[b]{2}{*}{$\begin{array}{l}\text { Expected } \\
\text { ratio }\end{array}$} & \multirow[b]{2}{*}{$\chi^{2}$} & \multirow[b]{2}{*}{$P$} \\
\hline & Total & $\begin{array}{c}\text { Low + } \\
\text { medium } \\
\text { sucrose }\end{array}$ & $\begin{array}{c}\text { High } \\
\text { sucrose }\end{array}$ & & & \\
\hline$\overline{\mathrm{P}_{1}, \mathrm{NY}}$ & 28 & 0 & 28 & --- & -- & --- \\
\hline $\mathrm{P}_{2}, \mathrm{FAQ}$ & 26 & 26 & 0 & --- & -- & -- \\
\hline $\mathrm{F}_{1}\left(\mathrm{P}_{2} \times \mathrm{P}_{1}\right)$ & 31 & 31 & 0 & -- & -- & -- \\
\hline $\mathrm{F}_{2}\left(\mathrm{P}_{2} \times \mathrm{P}_{1}\right) f$, Total & 359 & 277 & 82 & $3: 1$ & 0.892 & 0.34 \\
\hline $\mathrm{BC}_{1}\left(\mathrm{~F}_{1} \times \mathrm{P}_{1}\right), \mathrm{I}$ & 20 & 8 & 12 & $1: 1$ & 0.800 & 0.37 \\
\hline $\mathrm{BC}_{1}\left(\mathrm{~F}_{1} \times \mathrm{P}_{1}\right), \mathrm{II}$ & 40 & 19 & 21 & $1: 1$ & 0.100 & 0.75 \\
\hline $\mathrm{BC}_{1}\left(\mathrm{~F}_{1} \times \mathrm{P}_{1}\right)$, Total & 60 & 27 & 33 & $1: 1$ & 0.600 & 0.43 \\
\hline $\mathrm{BC}_{1}\left(\mathrm{~F}_{1} \times \mathrm{P}_{2}\right), \mathrm{I}$ & 14 & 14 & 0 & --- & --- & --- \\
\hline $\mathrm{BC}_{1}\left(\mathrm{~F}_{1} \times \mathrm{P}_{2}\right), \mathrm{II}$ & 13 & 13 & 0 & -- & --- & --- \\
\hline
\end{tabular}



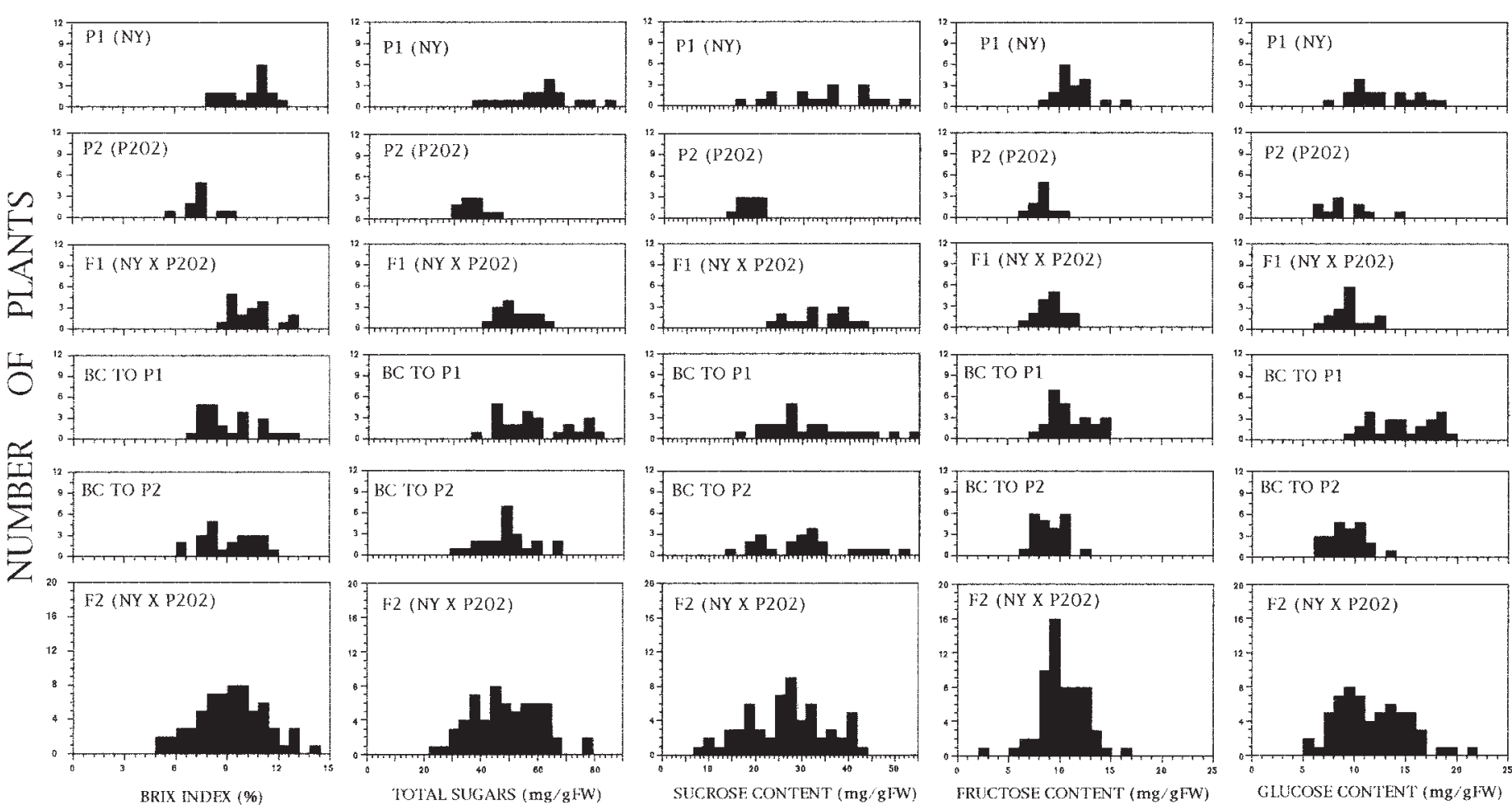

TOTAL SUGARS (mg/gFW)

SUCROSF CONTENT $(\mathbf{m g} / \mathrm{g} F W$ )

FRUCTOSE CONTENT (mg/gFW)

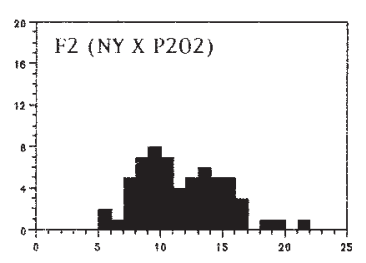

GLUCOSE CONTENT (mg/gFW)

Fig. 3. Frequency distribution of Brix, total soluble sugars, and individual sugars in progeny of populations based on NY and P202.

example, the citric and malic acid levels in tomato fruit (Stevens, 1972), starch levels in immature tomato fruit (Schaffer et al., 2000a) and sugar levels in ripe tomato fruit (Fridman et al., 2000; Levin et al., 2000).

The inheritance of sugar levels in the intermediate $x$ high sugar populations appears to be more complex and the populations studied do not present a clear segregation pattern of simple genetic control. There appear to be dominance factors for high sucrose levels based on the means of the $\mathrm{F}_{1}$ and $\mathrm{BC}$ populations but there is no clear segregation pattern pointing to a small number of genes. The heritability estimates for the soluble sugars, including sucrose, are accordingly low, although the heritability data indicate that progress can be made in increasing the sugar levels of the moderate-sugar genotype. The absence of FAQ-like low sucrose segregates in the P202 $\times$ NY populations suggests that P202 and NY have the same allele for high sucrose accumulation and differ primarily in other loci modifying sugar content.

Previously, comparative studies of sucrose accumulation in $C$. melo fruit compared high-sucrose genotypes to $\mathrm{P} 202$, a putative representative of low sucrose-accumulating genotypes (Hubbard et al., 1989, 1990; McCollum et al., 1988; Schaffer et al., 1987). The present study, comparing a high sucrose genotype with an extreme low sucrose genotype (FAQ) allowed for the discovery of a major gene controlling this important trait. Further comparative studies of sucrose metabolism in these extreme genotypes should shed light on the metabolic determinants of sucrose accumulation.

The central role of sucrose accumulation in explaining the genetic variability for total sugar levels in these segregating populations fits well with the general picture regarding the role of sucrose in determining sweetness in melon fruit. Previous results (Hubbard et al., 1989, 1990; McCollum et al., 1988; Schaffer et al., 1987; Stepansky et al., 1999) have shown that the wide range of sugar levels found in fruit of accessions of this highly polymorphic species is largely accounted for by differences in sucrose content. The broad range of sugar levels in homogenetic hybrid cultivars is also explained by differences in sucrose levels only (Burger et al., 2000). The latter observation is due mostly to nongenetic differences in fruit development and maturity, as well as inter- and intraplant factors, determined by the gamut of wholeplant source-sink relationships, including fruit-sink demand and competition (Schaffer et al., 1996). Our study of inheritance was carried out on field-grown plants and the number of fruit per plant was not controlled. Limiting the number of fruit per plant to a single fruit would no doubt have reduced the variability in the sucrose levels because it would have removed the factor of intraplant competition for photoassimilates (Schaffer et al., 1996).

Inheritance of sucrose accumulation has been studied in some other plant species, such as carrot (Freeman and Simon, 1983) and tomato (Chetelat et al., 1993; Hadas et al., 1995). However, in these cases the genetic control is over the partitioning of soluble sugars between hexose and sucrose, with little impact on total sugar levels. In contrast, the genetically determined accumulation of sucrose in C. melo is causal to the net increase in total sugar accumulation and does not determine merely the ratio of sucrose to hexose. In C. melo, the traits of sucrose levels and total sugar levels are inherently associated, as indicated by the absence of high-sugar segregants with low sucrose and high hexose levels. Nor does the high-sugar-hexose phenotype exist in C. melo in nature, as all high-sugar accessions of $C$. melo fruit, representing the broad range of the species, are characterized by high sucrose levels (Stepansky et al., 1999). This is in contrast to some other fruit that accumulate high levels of soluble sugar predominantly, or largely, in the form of hexose (i.e., grape, date, see Whiting, 1970).

The recessive nature of sucrose accumulation may contribute to our understanding of the evolution under domestication in $C$. melo. Two additional traits determining melon fruit taste, bitter and sour, are also under simple genetic control and in both cases the recessive trait leads to improved fruit taste of the mature fruit. 
Bitterness, determined by dominant Bif genes (Pitrat, 1998) is present primarily in wild C. melo types (Dewai et al., 1997; Kerje and Grum, 2000; Mallick and Masui, 1986) and presumably the recessive nonbitter trait was selected for very early in domestication. The acidic trait, determined by the dominant allele of the So gene (Kubicki, 1962; Pitrat, 1998) is found in melon types such as var.flexuosus or var. chate which are generally eaten at a young stage of fruit development, similar to a cucumber, before acid levels increase (Pitrat et al., 2000). The selection of three recessive traits, nonbitterness ( bif), nonsour (so) and sucrose accumulation $(s u c)$ characterize the domestication of the sweet melon fruit eaten when mature.

The onset of sucrose accumulation in melon fruit is a result of a metabolic transition in sugar metabolism in the developing fruit. Previous studies have presented evidence that sucrose metabolism in the fruit sink determines the onset of sucrose accumulation (Hubbard et al., 1989, 1990; Lester et al., 2001; Lingle and Dunlap, 1987; McCollum et al., 1989; Schaffer et al., 1987). In light of the simple genetic control of this process presented in this report, it is tempting to speculate that the gene controlling sucrose accumulation may encode for one of the components of the sucrose metabolism pathway (Schaffer et al., 1996, 2000b). Likely candidates for such genetic-metabolic control include the enzymes invertase, sucrose synthase, and sucrose phosphate synthase (Hubbard et al., 1989; Lester et al., 2001; McCollum et al., 1988; Schaffer et al., 1987) as well as the other enzymes involved in cucurbit fruit carbohydrate metabolism (Gao et al., 1999; Pharr and Hubbard, 1994; Schaffer et al., 1996, 2000b). The hexose and sucrose transporters present in sugar accumulating fruit (Ageorges et al., 2000; Davies, et al., 1999; Fillion et al., 1999; Gear et al., 2000) are similarly likely candidates. The availability of characterized segregating populations between the extreme sugar accumulating phenotypes will allow for the further study of the genetic-metabolic control of this important horticultural and metabolic trait.

\section{Literature Cited}

Ageorges, A., N. Issaly, S. Picaud, S. Delrot, and C. Romieu. 2000. Identification and functional expression in yeast of a grape berry sucrose carrier. Plant Physiol. Biochem. 38:177-185.

Burger, Y., S. Shen, M. Petreikov, and A.A Schaffer. 2000. The contribution of sucrose to total sugar content in melons. In: N. Katzir and H.S. Paris (eds.). Proc. Cucurbitaceae 2000. Acta Hort. 510:479-485.

Chetelat, R.T., E. Klann, J.W. De Verna, S. Yells, and A.B. Bennett. 1993. Inheritance and genetic mapping of fruit sucrose accumulation in Lycopersicon chmielewskii. Plant J. 4:643-650.

Davies, C., T. Wolf, and S.P. Robinson. 1999. Three putative sucrose transporters are differentially expressed in grapevine tissues. Plant Sci. 147:93-100.

Dewei, M., S. Lan, L. Y. Hui, Z. Yanping, and L. Haihe. 1997. A genetic model of bitter taste in young fruits of melon. Cucurbit Genet. Coop. Rpt. 20:27-29.

Falconer, D.S. 1995. Introduction to quantitative genetics. $4^{\text {th }}$ ed. Longman, London.

Fillion L, A. Ageorges, S. Picaud, P. Coutos-Thevenot, R. Lemoine, C. Romieu, and S. Delrot. 1999. Cloning and expression of a hexose transporter gene expressed during the ripening of grape berry. Plant Physiol. 120:1083-1094.

Freeman, R.G. and W.P. Simon. 1983. Evidence for simple control of sugar type in carrot (Daucus carota L.). J. Amer. Soc. Hort. Sci. 108:50-54.

Fridman, E., T. Pleban, and D. Zamir. 2000. A recombination hotspot delimits a wild species quantitative trait locus for tomato sugar content to $484 \mathrm{bp}$ within an invertase gene. Proc. Natl. Acad. Sci. USA 97:4718-4723.

Gao, Z., M. Petreikov, E. Zamski, and A.A. Schaffer. 1999. Carbohydrate metabolism during early fruit development of sweet melon (Cucumis melo). Physiol. Plant. 106:1-8.

Gear, M.L., M.L. McPhillips, J.W. Patrick, and D.W. McCurdy. 2000. Hexose transporters of tomato: Molecular cloning, expression analysis and functional characterization. Plant Mol. Biol. 44:687-697.

Hadas, R., A.A. Schaffer, D. Miron, M. Fogelman, and D. Granot. 1995. PCRgenerated molecular markers for the invertase gene and sucrose accumulation in tomato. Theor. Appl. Genet. 90:1142-1148.

Hubbard, N.L., S.C. Huber, and D.M. Pharr. 1989. Sucrose phosphate synthase and acid invertase as determinants of sucrose concentration in developing muskmelon (Cucumis melo L.) fruits. Plant Physiol. 91:1527-1534.

Hubbard, N.L. S.C. Huber, and D.M. Pharr.1990. Sucrose metabolism in ripening fruits as affected by leaf area. J. Amer. Soc. Hort. Sci. 115:798-802.

Hughes, D.L. and M. Yamaguchi. 1983. Identification and distrubution of some carbohydrates of the muskmelon plant. HortScience 18:739-740.

Kerje, T. and M. Grum. 2000. The origin of melon, Cucumis melo: a review of the literature. In: N. Katzir and H.S. Paris (eds.). Proc. Cucurbitaceae 2000. Acta Hort. 510:37-44.

Kubicki, B. 1962. Inheritance of some characters in muskmelons (Cucumis melo L.). Genet. Polonica 3:265-274.

Lester, G.E. and J.R. Dunlap. 1985. Physiological changes during development and ripening of 'Perlita' muskmelon fruits. Scientia Hort. 26:323-331.

Lester, G.E., L.S.S. Arias, and M. Gomez-Lim. 2001. Muskmelon fruit soluble acid invertase and polypeptide profiles during growth and maturation. J. Amer. Soc. Hort. Sci. 126:33-36.

Levin, I., N. Gilboa, E. Yeselson, S. Shen, and A.A. Schaffer. 2000. Fgr, a major locus that modulates the fructose to glucose ratio in mature tomato fruits. Theor. Appl. Genet. 100:256-262.

Lingle, S. and J.R. Dunlap. 1987. Sucrose metabolism in netted muskmelon fruit during development. Plant Physiol. 84:386-389.

Mallick, M.F.R. and M. Masui. 1986. Origin, distribution and taxonomy of melons. Scientia Hort. 28:251-261.

McCollum, T.G., D.J. Huber, and D.J. Cantliffe. 1988. Soluble sugar accumulation and activity of related enzymes during muskmelon fruit development. J. Amer. Soc. Hort. Sci. 113:399-403.

Miron, D. and A.A. Schaffer. 1991. Sucrose phosphate synthase, sucrose synthase invertase activities in developing fruit of Lycopersicon esculentum Mill. and the sucrose accumulating Lycopersicon hirsutum Humb. and Bonpl. Plant Physiol. 95:623-627.

Paris, H.S., T.G. McCollum, H. Nerson, D.J. Cantliffe, and Z. Karchi. 1985. Breeding of concentrated-yield muskmelons. J. Hort. Sci. 60:335-339.

Pharr, D.M. and N.L. Hubbard. 1994. Melon: Biochemical and physiological control of sugar accumulation. Encyclo. Agr. Sci. 3:25-37.

Pitrat, M. 1998. 1998 gene list for melon. Cucurbit Genet. Coop. Rpt. 21:69-81.

Pitrat, M., P. Hanelt and K. Hammer. 2000. Some comments on infraspecific classification of cultivars of melon. In: N. Katzir and H.S. Paris (eds.). Proc. Cucurbitaceae 2000. Acta Hort. 510:29-36.

Pratt, H.K. 1971. Melons, p. 207-232. In: A.C. Hulme (ed.). The biochemistry of fruit and their products. vol. 2. Academic Press, New York.

Rosa, J.T. 1928. Change in composition during ripening and storage of melons. Hilgardia 3:421-443.

Schaffer, A.A., B. Aloni, and E. Fogelman. 1987. Sucrose metabolism and accumulation in developing fruit of Cucumis. Phytochemistry 26:1883-1887.

Schaffer, A.A., D.M. Pharr, and M.A. Madore. 1996. Cucurbits, p. 729-757. In: E. Zamski and A.A. Schaffer (eds.). Photoassimilate distribution in plants and crops. Marcel Dekker, New York.

Schaffer, A.A., I. Levin, I. Oguz, M. Petreikov, F. Cincarevsky, Y. Yeselson, S. Shen, N. Gilboa, and M. Bar. 2000a. ADPglucose pyrophosphorylase activity and starch accumulation in immature fruit: The effect of a Lycopersicon hirsutumderived introgression encoding for the large subunit. Plant Sci. 152:135-144.

Schaffer, A.A., Y. Burger, G. Zhang, Z. Gao, D. Granot, M. Petreikov, L. Yeselson, and S. Shen. 2000b. Biochemistry of sugar metabolism in melons as related to the genetic improvement of fruit quality. In: N. Katzir and H.S. Paris (eds.). Proc. Cucurbitaceae 2000. Acta Hort. 510:449-453.

Stepansky, A., I. Kovalski, A.A. Schaffer, and R. Perl-Ttreves. 1999. Variation in sugar levels and invertase activity in mature fruit representing a broad spectrum of Cucumis melo genotypes. Genet. Resrc. Crop Evol. 45:53-62.

Stevens, M.A. 1972. Citrate and malate concentrations in tomato fruits: genetic control and maturational effects. J. Amer. Soc. Hort. Sci. 97:655-658.

Yamaguchi, M., D.L. Hughes, K. Yabumoto, and W.C. Jennings. 1977. Quality of cantaloupes: Variability and attributes. Sci. Hort. 6:59-70.

Whiting, G.C. 1970. Sugars, p. 1-31. In: A.C.Hulme (ed.). The biochemistry of fruit and their products. vol. 1. Academic Press, New York. 